\title{
Hybridisation, Personalisation and Tribuneship in the Political Interview ${ }^{1}$
}

\author{
IAN HUTCHBY \\ University of Leicester
}

\begin{abstract}
This article presents a comparative analysis of political interviewing in the contemporary environment of broadcast news. Beginning from a conversation analytic perspective, four types of political interview programme are described in terms of their different approaches to questions and answers; opinions and arguments; and neutrality, agency and advocacy. The analysis then turns to the different ways in which 'tribuneship' is manifested in different types of interview, comparing the representation of the public interest as found in both neutralistic and adversarial interviewing with the type of personalised and 'non-neutral' tribuneship found in hybrid political interviews.
\end{abstract}

\section{Keywords}

Controversy; hybrid media; infotainment; media talk; news interviews; political broadcasting; tribuneship

The landscape of broadcast political news is changing, partly under the influence of changing technology, but also due to changes in approaches to the social role of television journalism. For some, the development of new, hybrid news formats is linked to the confluence of digitisation and deregulation in broadcasting policy that has led to a proliferation of news channels running 24 hours a day, seven days a week, and serving niche as well as generic public interests (Silvia, 2001). The resultant 'global news' culture is then discussed by media

\footnotetext{
${ }^{1}$ This article is based on a keynote speech presented at the conference 'Hybridity and the News: Hybrid Forms of Journalism in the 21st Century' held at the Brussels Institute for Journalism Studies, Vrije Universiteit Brussel, Belgium. My thanks to the organisers for their invitation and hospitality, and to the conference delegates for their useful contributions to the discussion of my paper.
} 
sociologists in terms of wider trends in which broadcasting is critiqued for its increasing marketisation, and the shaping of its output by commercial and corporate agendas into the hybrid forms of 'infotainment' (Thussu, 2007). Many of the journalistic practices of cable and satellite news are less constrained by the commitment to impartiality and objectivity that is often written into the licensing agreements of public service-oriented news channels. For some analysts (Meehan, 2005; Thussu, 2007), the blending of information and entertainment in the former context is simultaneously aligned with the influence of business interests and, specifically, the promulgation of conservative or populist ideas.

In the present article, I take a different approach to understanding these types of hybrid news formats; in particular the forms of 'opinionated' news presentation currently found primarily on US-based cable news channels. In line with the general perspective of conversation analysis (Hutchby and Wooffitt, 2008), I argue that to understand fully how trends towards infotainment, confrontainment, and other hybrid genres impact on the nature of broadcast political journalism, as well as on the role of broadcasting in the democratic process, we need to engage in detailed investigation of the talk-in-interaction that makes up much of the news discourse itself.

Conversation analysis (CA) takes as its starting point a focus on turn-taking and the organisation of sequences of activities in both conversational and institutional (for example, news interview) contexts. From this perspective, a wide variety of aspects of news interview conduct have previously been described, ranging from the basic ways in which the turntaking format is managed (Greatbatch, 1988); to the means by which interviewees seek to shift the agendas pursued in interviewers' questions (Greatbatch, 1986); to the crucial processes of 'neutralism' - the ways in which interviewers challenge interviewees without adopting positions in their own right (Clayman, 1988, 1992; see also Clayman, 1989; Clayman and Heritage, 2002; Clayman and Whalen, 1988/9; Greatbatch, 1986; Heritage, 1985; Pomerantz, 1988/89; Rendle-Short, 2007; Schegloff, 1988/89). In terms of understanding different news formats, the basic standpoint of CA studies is that 'the interactional structures through which broadcast news is conveyed must necessarily contribute to the content and appearance of news messages' (Heritage et al, 1980: 80). 
Most CA work, alongside related work by social psychologists (Bull, 2008) and linguists (Harris, 1991), has focused on the genre of 'political interview'. However, Montgomery (2007) has argued that we should view news interviewing through a wider lens, situating the interview within its specific broadcast context, namely the range of discourses that constitute 'broadcast news'. Within this context, he argues, the focus on political interviewing has been too restrictive, overshadowing the extent to which news interviews are also about personal testimony, on-the-spot correspondence and eyewitness reports. Within their broader framework of news production, news broadcasts utilise a range of interview types that differ depending on whether the interviewer is in the studio or on location at the scene, or according to the identity of the interviewee in relation to the event being reported upon.

Thus, the 'expert' interview involves a professional journalist and a professional representative of some important body (the government, a business organisation, the health service, and so on). The 'experiential' interview involves a professional journalist and a lay person, such as an eye-witness at a newsworthy event. The 'affiliated' interview involves two (or more) professional journalists: one in the studio, another at the scene of a newsworthy event. Here in particular the question-answer structure can become more informal as the onlocation journalist relays, often extempore, their interpretation of the latest events in interaction with the studio anchor. Finally the 'accountability' interview is defined by the type of interaction between the professional journalist and the interviewee; namely that the latter is being 'held to account', often in adversarial terms, for actions or statements which the interviewer treats as somehow controversial.

Montgomery's analysis is persuasive, and his typology is useful in enabling the inclusion of interviews that are not about politics or concerning political issues. However, it is worth pointing out that each of his categories can also, in context, act as the vehicle for a political interview. This is especially so if we adopt a wider definition in which a 'political interview' is not simply one involving a politician, but one which involves any matter of political concern; for example, same-sex marriage, public finance, abortion law, and so on.

The category of political interview itself, therefore, needs to be understood in a more 
variegated way. This is even more the case if we take into account the range of broadcast contexts in which political interviews occur. In the current environment of televised news (leaving aside for the present online environments), the political interview is not something that takes place solely within the 'official' format of mainstream news broadcasting. Alongside the more conventional political interviews analysed in earlier work, we need to incorporate non-mainstream hybrid and reflexive forms in which challenges to the normative interview format and the premisses of journalistic neutrality are being mounted in contemporary broadcasting.

In recent years, especially on the US-based cable channels, the latter have become increasingly significant, with shows such as Fox News' nightly O'Reilly Factor regularly attracting audiences of 1.5-2 million. ${ }^{2}$ Other main cable news channels in the US draw slightly smaller audiences: just under 620,000 at MSNBC and 540,000 at CNN. ${ }^{3}$ However, this still places them broadly in line with mainstream British news viewing figures: for example the BBC's flagship Newsnight draws an average nightly audience of 590,000 (albeit from a much smaller total population).

It seems clear, therefore, that we need to incorporate these and other programme formats into a more nuanced, as well as more global, definition of 'the political interview' as a media discourse form.

The present analysis draws upon a collection of interviews recorded between 2009-15 from mainstream news broadcasting and from programmes that sit outside the mainstream, incorporating material from both British and North American television media. ${ }^{5}$ The recordings were made as part of an ongoing project investigating the changing nature of broadcast political discourse, and included flagship news broadcasts such as BBC television's Newsnight, ITN's Six O'Clock News and News At Ten, and BBC Radio's daily Today Programme. Other interviews were drawn from more specialised lunchtime and late evening

\footnotetext{
${ }^{2}$ Viewing figures from Nielsen Media Research, cited by Mediaite.com, October 2014.

${ }^{3}$ Viewing figures from Nielsen Media Research, cited by Journalism.org, October 2014.

${ }^{4}$ Viewing figures from the British Broadcasting Corporation, cited by Broadcastnow.co.uk, April 2014.

${ }^{5}$ The collection was not intended to be a fully representative sample of political interview broadcasts. Neither was the sampling in this case designed to enable a systematic comparison between UK and US news broadcasts.
} 
news shows such as BBC's Daily Politics and This Week. Finally, a collection of interviews were recorded from US cable news programming such as Fox News' The O'Reilly Factor and Hannity, and news broadcasts on other cable channels such as CNN and MSNBC. These broadcasts are widely accessible via the internet and satellite television.

I begin by outlining four categories of 'political news interview' that can currently be found in the broadcast media. I call these the conventional, the adversarial, the hybrid, and the reflexive types of political interview. The four types I discuss are defined in a slightly different way to Montgomery's (2007) typology. Using the conversation analytic concept of speech exchange systems, or turn-taking structures (Sacks et al, 1974), I begin from the standpoint that the interview per se is a speech exchange system that can be defined systematically in terms of its distinction from ordinary conversation (Greatbatch, 1988). The other types are then seen as variations of that baseline exchange system; incorporating, to a greater or lesser extent, speech patterns from turn-taking systems associated with social contexts other than the interview.

\section{Four types of interview}

In the conventional political interview (CPI), both interviewer and interviewee comply in observing fairly strict conventions both on how to take turns at speaking, and on what topics can be discussed. It is a format in which the basic turn-taking structure of the interview is most closely adhered to. This turn-taking structure is characterised by two main types of sequence that, as early work in conversation analysis showed, are uniquely adapted to the professional journalistic constraints of neutralism: question-answer-next question (the avoidance of third-turn acknowledgement of interviewees' answers); and question-answerformulation (use of third-turn summaries to suggest rewordings and sometimes challenges to interviewees' answers) (Clayman, 1992; Greatbatch, 1988; Heritage, 1985). This conventional interview type emerged in the early days of broadcasting (Schudson, 1994) but can still be found in many broadcast contexts today.

In the adversarial political interview (API), public figures are subject to lines of 
questioning that often take the appearance of the forms of talk found in courtroom crossexamination. As Atkinson and Drew (1979) pointed out, while the examination and crossexamination of witnesses is organised according to a question-answer speech exchange system, that is only a minimal characterisation of what is going on in individual turns. Any of a range of adversarial actions may be done in a given turn (mounting an accusation, imputing bad character, exhibiting skepticism, or defending against any of these actions), provided that they are done in the form of a question or answer. Montgomery (2007: 206) points out that one of the earliest proponents of adversarial interviewing on British TV, Sir Robin Day, originally had a background as a courtroom advocate. Many leading British politicians also have training and sometimes practical experience as attorneys, and can be adept at using similar methods in challenging or resisting the interviewer's line of questioning. ${ }^{6}$

The line between the CPI and API can sometimes be blurred: for instance, interviewers' use of 'formulations' (see below) can be either cooperative or adversarial (Heritage, 1985). Both Clayman and Heritage (2002) and Montgomery (2007) give attention to adversarial as well as conventional interview formats; and there is a related range of work in discourse analysis and social psychology focussing on interviewee evasiveness and combative interview question design (Bull, 2008; Harris, 1991). As noted, Montgomery (2007) defines a particularly aggressive form of adversarial interview as the 'accountability' interview.

The hybrid political interview (HPI) combines adversarial techniques with features of discourse genres from outside political news broadcasting; for example, talk radio (Hutchby, 1996). In this format, the question-answer structure of the CPI is retained to some extent, but the interviewer (sometimes the interviewee too) freely moves between that structure and forms of talk that are more closely associated with arguing than with interviewing (Hutchby, 2011a). The norms of journalistic neutralism that are central to the CPI and, to some extent, the API can be more or less dispensed with in the HPI (Hutchby, 2011b). This in turn, it has

\footnotetext{
${ }^{6}$ A classic example is the May, 1997 interview between BBC journalist Jeremy Paxman and then Home Secretary Michael Howard (see Matheson, 2005: 121-123). https://www.youtube.com/watch?v=Uwlsd8RAoqI (Accessed October 2015).
} 
been argued, has implications for the relationship between broadcast journalism, politics, and the representation of public interest (Lauerbach, 2004; Patrona, 2011).

Finally, there is a fourth type that I refer to as the reflexive political interview (RPI). In certain programmes, usually in a late evening slot and often in an 'infotainment' format, political commentators, ex-politicians, talk show hosts or entertainers interview political figures, usually about policies or events as they have unfolded that day or week (for example, in the UK, the BBC's weekly This Week program hosted by veteran journalist Andrew Neil). These interviews retain a loose orientation to a question-answer turn-taking format, but the talk of both interviewers and interviewees typically takes on a quasi-conversational structure; appearing as much informal chat as formal interview.

Importantly, these are interviews in which the protagonists overtly display a knowingness about their own role in the mediation of news: hence the term 'reflexive'. To some degree, the live two-way 'affiliated' interview between news presenters and on-location correspondents analysed by Montgomery (2007) displays reflexive features. As he notes, the live two-way exhibits a 'greater degree of colloquial and idiomatic speech than in studio presentation' (2007: 124) while its relationship to the facticity of news is characterised by its 'informality and improvisational brio' (2007: 130). Other key types of reflexive political interview include programmes in which interview turn-taking systems are merged with the genres of comedy and satire (for example, The Daily Show hosted in the US for many years by actor Jon Stewart) (Baym, 2013); and chat show-based interviews hosted by celebrities in which ironic and playful forms of questioning are used to try and reveal 'authentic' aspects of politicians' personae (Ekstrom, 2011).

\section{The hybrid political interview}

The rest of this article illustrates and explores some of the key characteristics of the third of these types, the Hybrid Political Interview. This is a broadcast news format in which the interviewer feels able to dispense with most if not all of the norms of journalistic neutralism when he or she considers it necessary in the interests of advocating 'the truth'; or to put it 
slightly less contentiously, when engaging in tribuneship: an issue discussed in more detail below.

The kind of hybridisation involved in the HPI is a merging of speech exchange systems from two forms of institutional discourse: the news interview (Clayman and Heritage, 2002) and the talk radio show (Hutchby, 1996). The speech exchange systems involved are those constitutive of, respectively, interview and argument. The interview turntaking structure is one of question and answer; and in the HPI interviewers do put questions to interviewees who are expected to answer them. However, unlike conventional news interviews, interviewers routinely engage in evaluating and taking issue with interviewees' answers; such that the characteristic turn-taking structure of the argumentative talk radio show, the action-opposition sequence, merges with and in many cases overrides the questionanswer sequence.

At the same time, there is a hybridisation of visual as well as verbal institutional conventions. The generic conventions of the televised interview are used to identify the event as 'broadcast news'. The interviewer dresses formally, sits at a desk directly facing the camera, and provides continuity between items as an 'anchor'. News items themselves are framed and contextualised using introductory scripted statements, video footage of relevant events, and formal introduction of interviewees, who themselves dress formally and sit either in the studio with the interviewer, or in a remote broadcasting studio shown in a caption or cutaway shot when it is their turn to speak.

However, the conventions of a different form of institutional discourse, the confrontational television or radio 'discussion' show (Hutchby, 1996; Tolson, 2001) also come into play as the interview becomes more opinionated and aggressive. For example, as seen further below, we find increasing levels of overlapping talk. In addition, emotionally heightened behaviours, such as raised voices and belligerent body language, are often employed, especially by the interviewer who may gesticulate (for instance with a jabbing index finger) towards the interviewee - or, if the interviewee is in a remote location, towards the camera (hence towards the screen which the audience member is watching).

The HPI to some degree has affinities with what Montgomery (2007) described as the 
accountability interview (a form of API). Among the similarities between the two types are the following:

1. Leading questions: Opening questions are often 'leading' - or formulated as first moves in assertion/counter-assertion sequences.

2. Repetition: Interviews can revolve around a single question or implied accusation which is put repeatedly and evaded by the interviewee; or is not answered to the interviewer's satisfaction.

3. Demeanor differentiation: Interviewees often observably orient to the aggressive demeanour or adversarial behaviour of the interviewer. They may seek to topicalise it or distinguish their 'reasonable' attempts to conduct an interview with the interviewer's 'unreasonableness'.

4. Non-resolution: Interviews often end on an unresolved note. Interviewers can make it clear that the question around which interview has been based has not been answered; or has been answered but manifestly not to their satisfaction or, by implication, that of the audience.

However, my aim is to focus principally on the dimensions along which the HPI differs from the accountability interview. To do that, it is useful to look at one example of an HPI interviewer (IR) 'taking issue' with something an interviewee (IE) says in this kind of context.

\section{'This is unbelievable': Taking issue in the hybrid political interview}

The IE in the following extract is a feminist who runs an online magazine. She is being interviewed on the topic of whether feminists should intervene in a debate sparked by responses to a beauty pageant queen (Carrie Prejean), who had been stripped of her title after public statements in which she expressed opposition to the legalisation of same-sex marriage.

Once she has introduced the upcoming interviewee, the IR opens the interview in the following manner: 


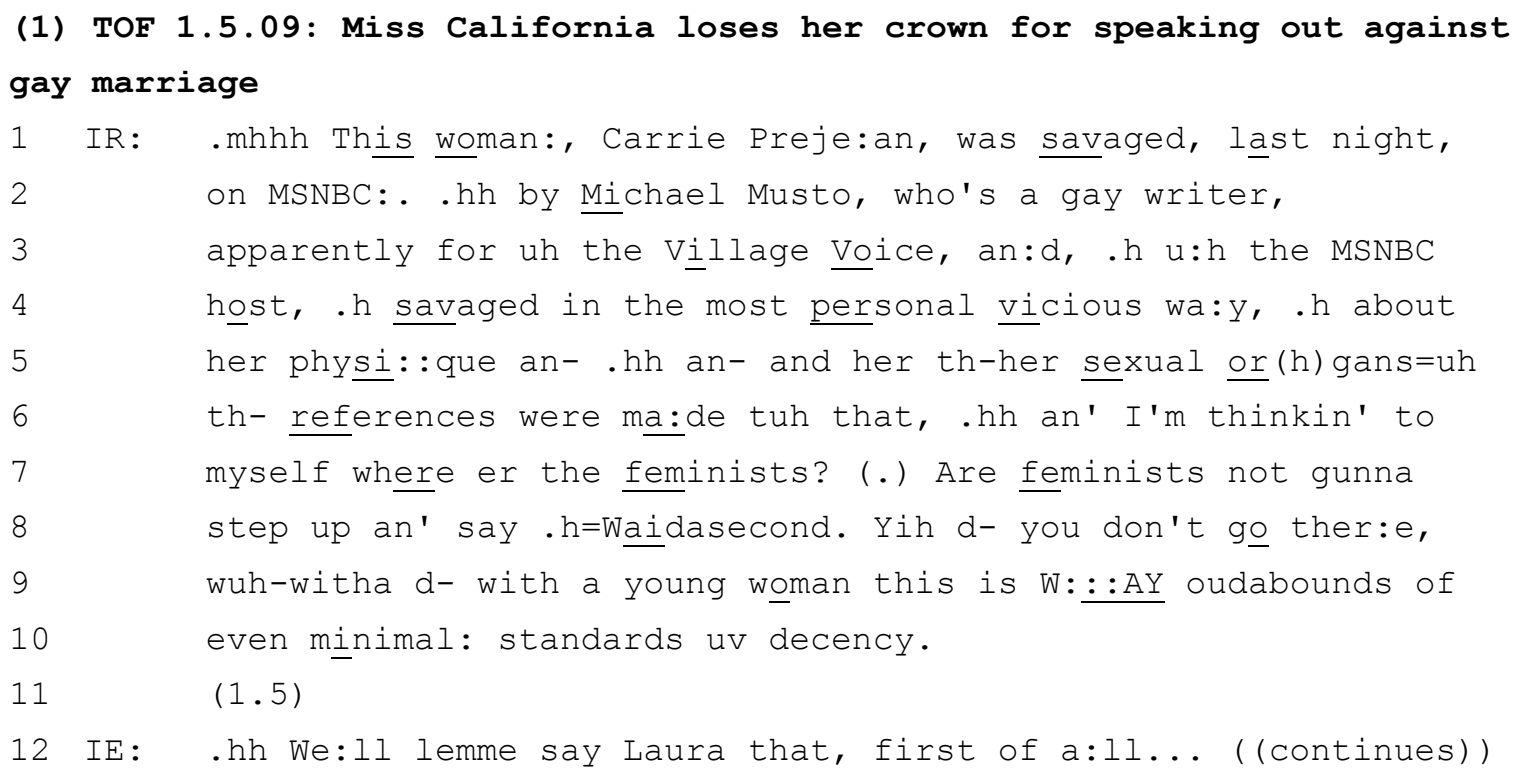

In lines 1-10, the IR's turn does not take the form of a grammatically recognisable question, but acts as a preamble which at least implicitly positions the IR herself in relation to the issue to be discussed. ${ }^{7}$ She refers to Ms Prejean being 'savaged' in 'personal vicious' ways by the 'gay writer' Michael Musto ${ }^{8}$ who along with the MSNBC host had responded to this story by mocking the 'physi::que and...sexual or(h)gans' of Ms Prejean. She then poses a rhetorical question as to why feminists were not defending Ms Prejean against such attacks which she describes as 'W:::AY oudabounds'. The pause in line 11, preceding the IE's first turn, is indicative of a possible problem the IE has in identifying the point at which the opening 'question' has therefore been posed.

Not only is the IR's opening turn full of evaluative phrases; it is also 'loaded' in that it positions the IE, an avowed liberal feminist, in a potentially contradictory position. As a liberal, she could be expected to disagree with Ms Prejean's opposition to gay marriage, and thus align with her critics on MSNBC; yet as a feminist, she could be expected to defend Ms Prejean as a woman against sexist comments, and thus align with her against those same critics.

Extract (2) shows the IE's attempt to construct an answer; and more significantly for

\footnotetext{
${ }^{7}$ See also Hutchby (2013) for an account of how HPI interviewers build tendentious opening questions.

${ }^{8}$ The Village Voice is an alternative, sometimes controversial, cultural magazine based in New York.
} 
present purposes, the IR's response to that attempt:

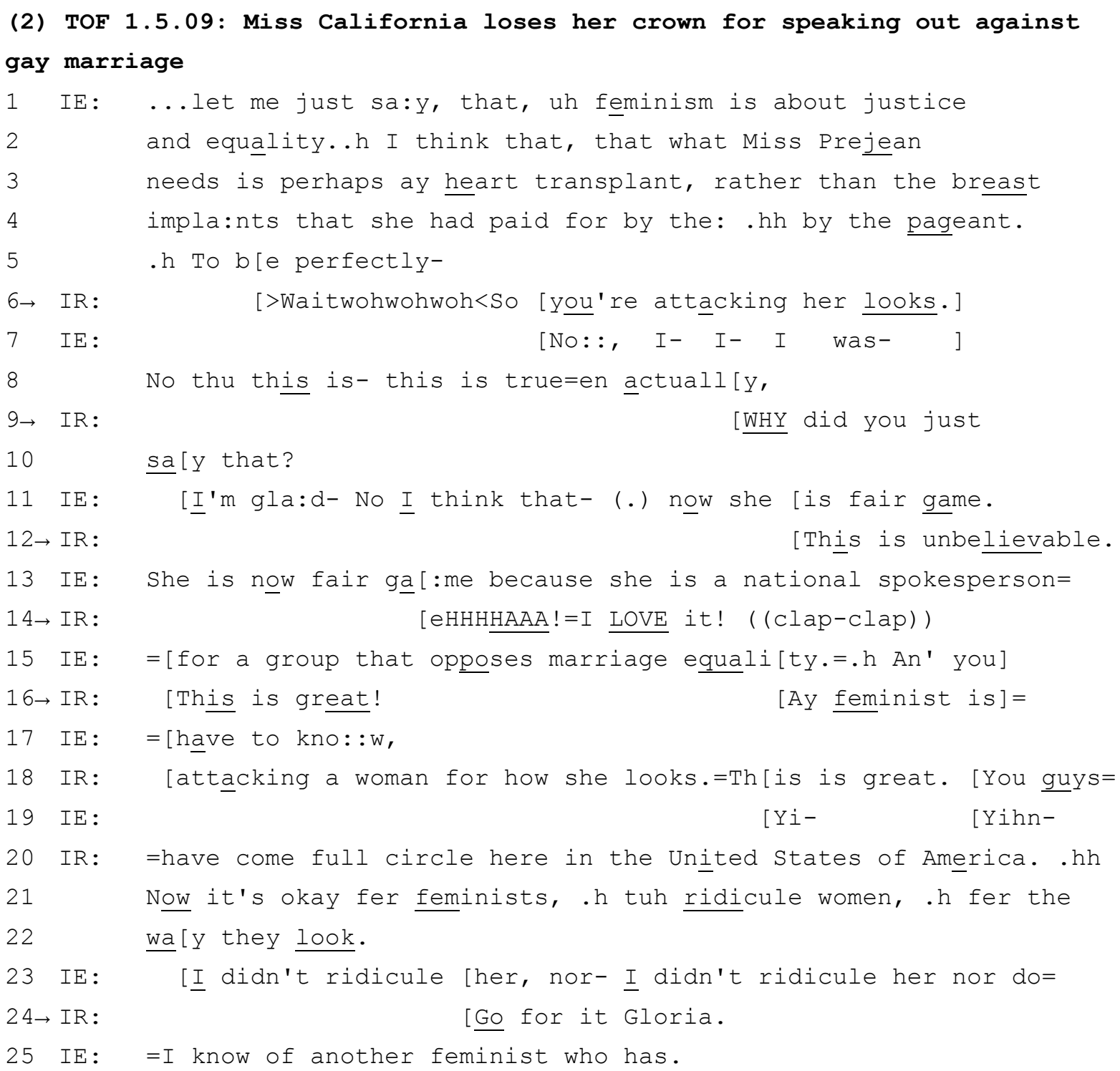

The IE's answer in lines 1-5 attempts, utilising the contrastive device 'heart transplant'/'breast implants', to suggest that Ms Prejean should show greater compassion or recognition of difference. However, the reference to her 'breast implants' in fact plays into the tendentious way the question had originally been set up by the IR, by appearing to collude with other media commentators who had been critical of Ms Prejean on physical terms.

It is at this point that the IR comes in (line 6) with an utterance that overtly attempts to curtail the IE's turn: 'Waitwohwohwoh'. This turn is produced interruptively in sequential terms, in that while there is a legitimate transition-relevance place (Sacks et al, 1974) after 
the IE's words 'by the pageant.', IE has sought to retain the floor with a continuation, '.h To $\mathrm{b}[\mathrm{e}$ perfectly-' (line 5). Yet the turn is also constructed so as to 'do' the work of 'being interruptive' in its syntax. Use of the word 'wait' indicates that the IR is expecting, or has heard, the IE's continuation with her turn; while the repeated expression 'wohwohwoh' seeks explicitly to arrest that continuation.

Following this, in news interview terms, non-standard intervention, the IR produces a standard type of interviewer turn, namely a formulation: 'So you're attacking her looks.' Heritage (1985) described formulations as turns which seek to summarize the gist or upshot of the previous utterance, and showed that they are frequently produced by news interviewers. Heritage argued that formulations may be neutralistic, in the sense that they avoid commenting on or making assessments of the content of a prior turn. However, he also showed that the 'inferentially elaborative' formulation may seek to 'make something more of [a topic] than was originally presented in the...prior turn' (1985: 101). In extract (1), the IR uses aspects of the IE's turn (the reference to 'breast impla:nts') to situate the IE in alignment with what have earlier been presented as the sexist comments of those opposed to her stance on gay marriage.

In news interviews, formulations are also turns that IEs seek to agree or disagree with in their next turn. In line 7, the IE attempts to disagree with the IR's formulation. Before the response can be elaborated, however, the IR comes in with what turns out to be the first in a series of interjections which follow on from the formulation (arrowed), all of which are produced in overlap with the IE's attempts to assert that Ms Prejean is 'fair ga:me because she is a national spokesperson for a group that opposes marriage equality.'

A key point about the IR's succession of utterances in lines 12, 14, 16 and 24 is that they are not attempts to put forward further questions to the IE about her position. Rather, they are expressions of a personal standpoint in relation to the view that has been formulated, by the IR herself, in line 6 . In this sense, it may be more accurate to say that the IR merely engages in 'argumentative talk', rather than the rational exchange of assertion and counterassertion that is sometimes posited as the basic structure of argument (Coulter, 1990).

The IR's series of overlapping utterances is similar to what Jefferson (1981: 14-18) 
described as the 'barrage': a combative practice whereby a speaker repeatedly solicits a response to a question, even where a response may in fact be underway. For example:

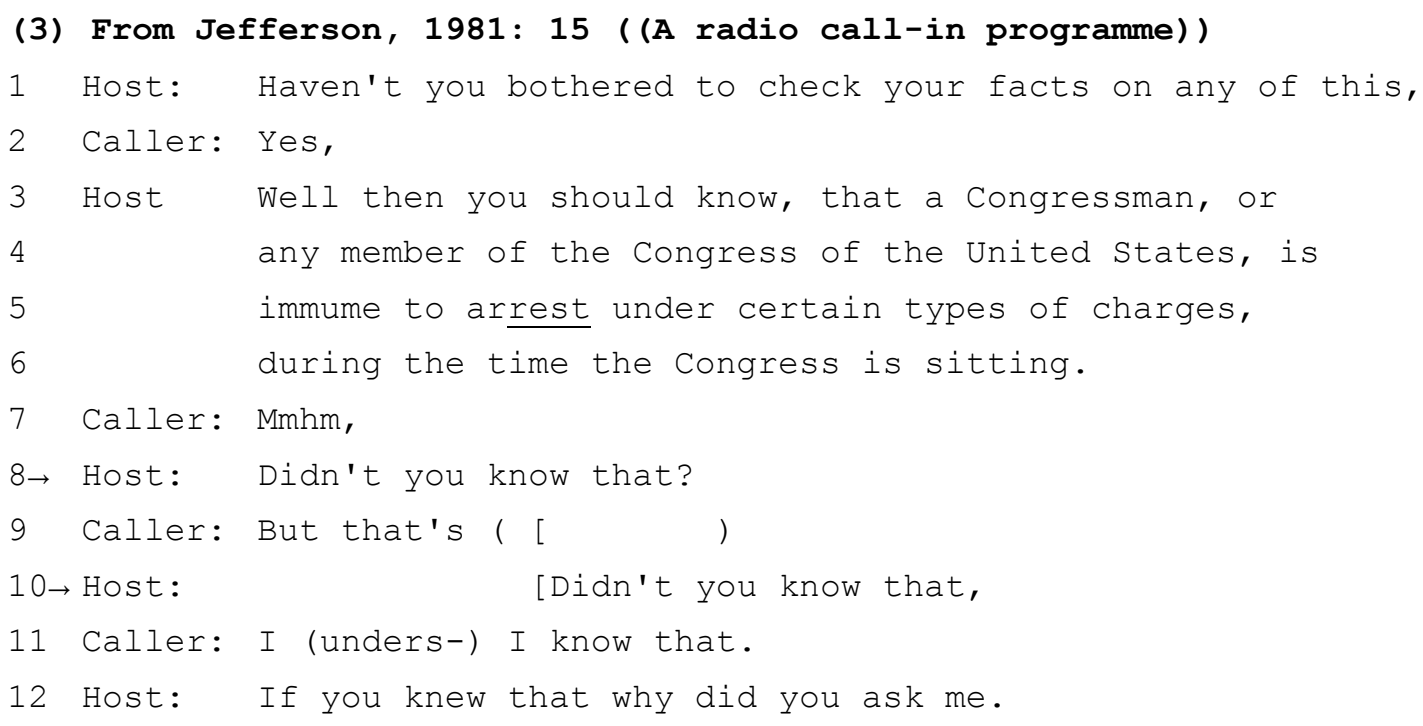

In the case of extract (2), the IR's barrage does not consist simply of response solicitations (though in line 9-10 we do find 'WHY did you just say that?'). Increasingly, the interjections become assertive or sarcastic evaluations ('This is unbelievable'; 'I LOVE it!'; 'This is great'; 'You guys have come full circle here in the United States of America'; 'Go for it Gloria'). Collectively, what this barrage aims to do is to prevent a counter-assertion or rebuttal, by means of the recycling of meta-comments on an attributed position (one which the IE, throughout, is attempting to disavow).

In more general terms, extract (2) illustrates a number of ways in which the HPI differs from the more mainstream, though still aggressive, API. These can be summarized as follows:

1. Personal stance-taking and evaluation: In the API, IRs may adopt personal standpoints, but still frequently use the adversarial technique of ending the turn with an interrogative (This is unacceptable, isn't it?' 'Isn't that the case?'). In the HPI, IRs may swiftly move from (loaded) opening questions to explicit personal stance-taking. (Extract 2 line 12: 'This is unbelievable.') 
2. Personal responsibility: In the API, the IE tends to be presented as attempting to subvert the norms of the interview by evading the question (Harris, 1991). They might be left to 'dig a hole' for themselves as the question is pursued. In the HPI, IEs are presented as personally responsible for holding/defending views that the IR personally takes issue with - in other words, even formalistic versions of journalistic neutralism can be dispensed with at certain stages in the HPI. (Extract 2 lines 21-4: 'Now it's okay fer feminists, .h tuh ridicule women... $\underline{\text { Go }}$ for it Gloria.')

3. Use of personal pro-terms: In the HPI, not only may IEs be personally associated with a contentious issue/statement/position by the use of 'you', but IRs will also readily use the pro-term 'I' to personalise the argument being conducted within the interview; IRs will openly associate themselves with standpoints in opposition to that of the IE (Extract 2 line 14's sarcastic 'eHHH $\underline{H A A A}$ !=I LOVE it!' ((clap-clap))).

4. Insults: Unlike in the API, in the HPI, the IR may readily subject the IE to personal insult, whether through name-calling ('You're a coward'; 'You're the zealot'; 'Your far left lunacy' (Hutchby, 2011a)) or through negative association (Extract 2 lines 16-18: 'Ay feminist is attacking a woman for how she looks').

5. Emotional heightening: In the API, emotional outbursts mainly come from IEs, who have been known to walk out of the interview; IRs typically remain calm, even when pursuing a question over numerous iterations. In the HPI, outbursts of emotion especially anger - more readily occur, but this time involving the IR; certain IRs take the licence to 'go ballistic', especially when faced with what they perceive as lying, evasiveness or other moral reprehensibility on the part of IEs. ${ }^{9}$ While IEs may occasionally respond with their own anger, much more frequently the IE tends to present a passive response to the outburst, manifesting verbal or paraverbal signals of 'powerlessness' in the face of the tirade.

A common factor here is personalisation; an issue that has been given some attention

\footnotetext{
${ }^{9}$ This is the case whether the IE is a minor figure or a senior government politician (Hutchby, 2011b).
} 
in recent studies of news interview discourse (Thornborrow and Montgomery, 2010). In these studies, one of the central themes is the way that personal matters, personal feelings or experiences can be brought into play in the expressly public sphere of the television interview. For example, Clayman (2010) shows how the use of IRs' personal names by IEs is often bound up with managing either expressive ('heartfelt') properties of talk or disjunctive (topic-shifting or disagreeing) turns in conventional news interviews.

In the HPI, by contrast, personalisation seems to be bound up with more extreme forms of disjuncture, within an overall context of belligerent and argumentative exchanges on socially controversial topics. In the remainder of this article, I explore how a further aspect of journalistic conduct, the practice of 'tribuneship', as used in the HPI contributes to a further level of personalisation in the public domain of media talk, emphasising the shift into argumentation and away from neutrality. In this sense, we can perhaps think of a continuum along which 'personalisation' functions in the evolution of broadcast news talk, from the increasing use of personal experience to contextualise major events (which itself perhaps evolves out of the original vox populi formats of early broadcasting (Corner, 1991)), to the use of alignment-saturated tribuneship formulations to highlight the argumentative nature of a hybrid interview.

\section{Tribuneship}

In the ancient Roman constitution, the 'tribuneship' was an elected office with responsibility for protecting the interests of the plebeians against the patrician senate. Later, as newspaper journalism developed in the $19^{\text {th }}$ and $20^{\text {th }}$ centuries, many newspapers adopted the name Tribune to convey a sense that they reported news in the interests of the ordinary people, as opposed to those of government or business. In the present article, the term tribuneship is used to refer to the ways in which broadcast news interviewers display, in the design and content of their questioning, an orientation towards their journalistic role as one of speaking for or representing the interests of ordinary people.

In many types of news interview, particularly adversarial and accountability 
interviews, IRs orient to their own self-presentation as representing the public interest, looking out for the underrepresented, seeking the truth, and so on. One way of doing this is for the IR to invoke the listening public as stakeholders, either directly or indirectly (e.g. 'people listening to this will want to know...'). For example:

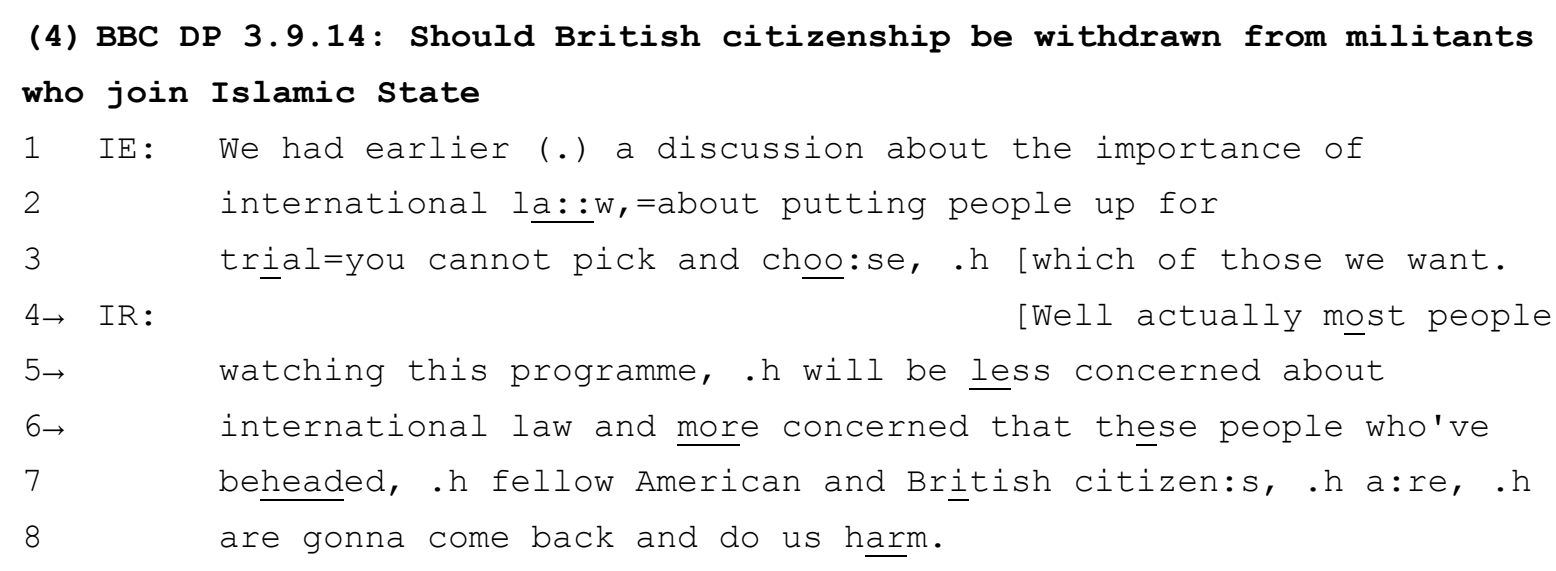

As Montgomery (2007: 179) puts it, in such instances interviewers move beyond conventional neutralism 'into a more populist stance in which interviewers - like tribunes of the people - ventriloquise on behalf of a presumed sceptical public.' This sense of ventriloquising, or speaking for a presumed public interest, lends this type of tribuneship a degree of neutralism. Like the conventional strategy of shifting footing (Clayman, 1992), in which the IR assigns authorship of controversial statements to third parties, ventriloquising enables the IR to be adversarial, even oppositional, whilst being seen to retain the professional journalistic standards of objectivity; avoiding the direct personal avowal of a position by attributing it instead to 'most people watching this programme'.

In the HPI, by contrast, tribuneship tends to be part of a more direct process in which the IR foregrounds his or her agency, spokespersonship, or expression of opinion in opposition to that of the interviewee. Moreover, the IR typically does not ventriloquise on behalf of a general viewing public; rather he or she constructs situationally specific sectoral interests to represent, or more strictly invoke, in the course of disputing with the IE.

In the following extract we find an example that is in some ways close to the API practice of invoking the public indirectly as stakeholders in the interview as pursuit of truth. 
However, that invocation of the sceptical public is placed within an overtly subjective evaluative framework:

(5) TOF 2.10.08: Did government regulation fail in the banking crisis

1 IE: The pro:blem was, that-we pa:ssed in nineteen ninety four in

2 fact, [the bill, (tuh take-)

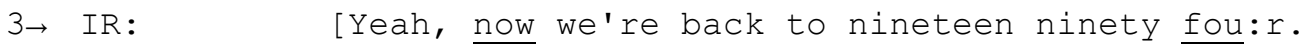

4 IE: Yes [we are because-

5 $\rightarrow$ IR: [This is bu::ll. .h [This is why Americans don't trust=

6 IE: $\quad[$ I'm ( ) (history)

7 IR: =the government.

8 IE: No: : this is where your stupidity gets in the way of

9 rational discussion. .h The fact is...

In line 5, the invocation of 'Americans' is preceded by an explicit and subjective evaluation of the IE's talk: 'This is bu::ll'. Thus, although the IR as tribune can speak for 'Americans' who 'don't trust the government', the spokespersonship is placed inside a framework of personal stance-taking involving insult. Note that the IE in this particular case returns the insult: 'this is where your stupidity gets in the way of rational discussion', thereby colluding momentarily in the interview's hybrid format.

In extract (6) we see the IR acting as advocate for 'a lotta people' who 'lost everything they ha:d' during the 2008 financial crash (line 4-5); but then invoking a wider listening public in a membership categorisation device 'we' (line 10):

(6) TOF 2.10.08: Did government regulation fail in the banking crisis

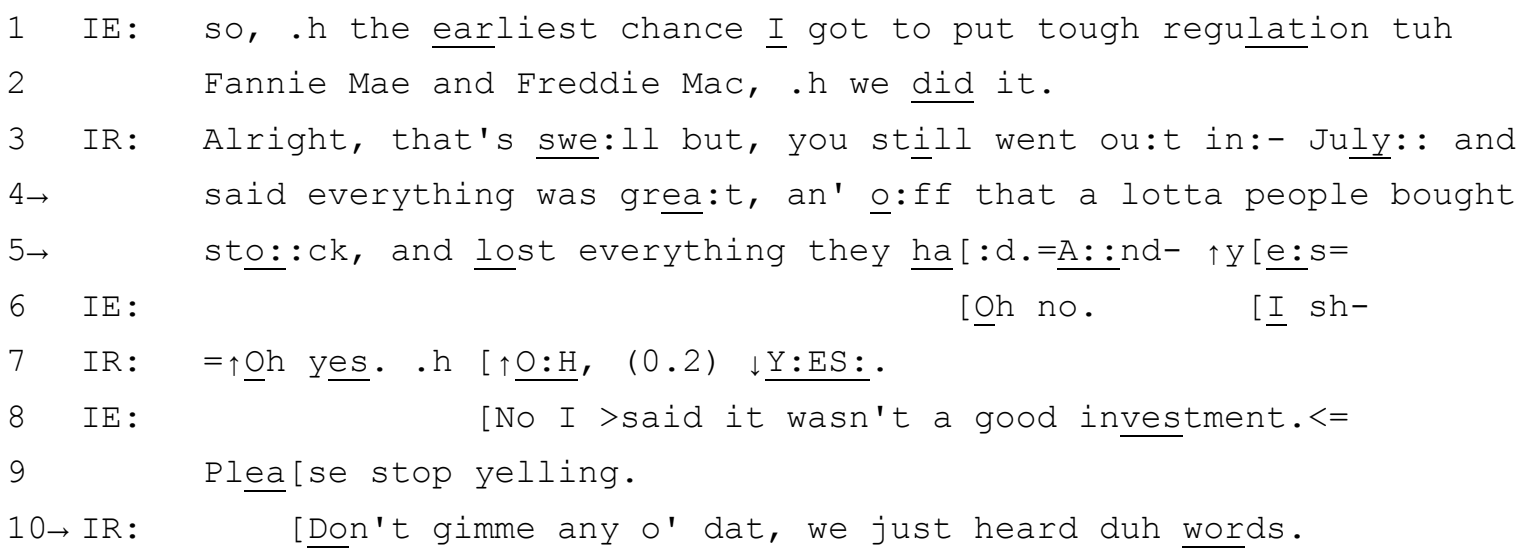


12 IE:

13 IR:

.h [What're you a- what're you-

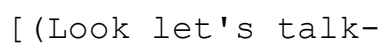

The IR refers here to a recording of a speech made by the IE which had been played prior to the interview. The use of the term 'we' in 'we just heard duh words' (line 10) functions to align the IR himself with the 'presumed sceptical public' in whose interests he proposes to be speaking. Thus, the tribune becomes not just a spokesperson for, but a member of the group who are in opposition to the IE's evasiveness.

The following extract similarly shows the IR speaking for a particular group in society, but also doing alignment work involving both herself and the IE (a civil rights lawyer). The subject here is the placing of military recruitment materials in schools. The IR's line of questioning has sought to establish that the IE's opposition to this practice is politically motivated, primarily on the grounds that the IE's organisation does not similarly object to the placing of what the IR calls 'left-wing' materials in schools.

(7) TOF 25.1.08: Should military recruitment in schools be banned

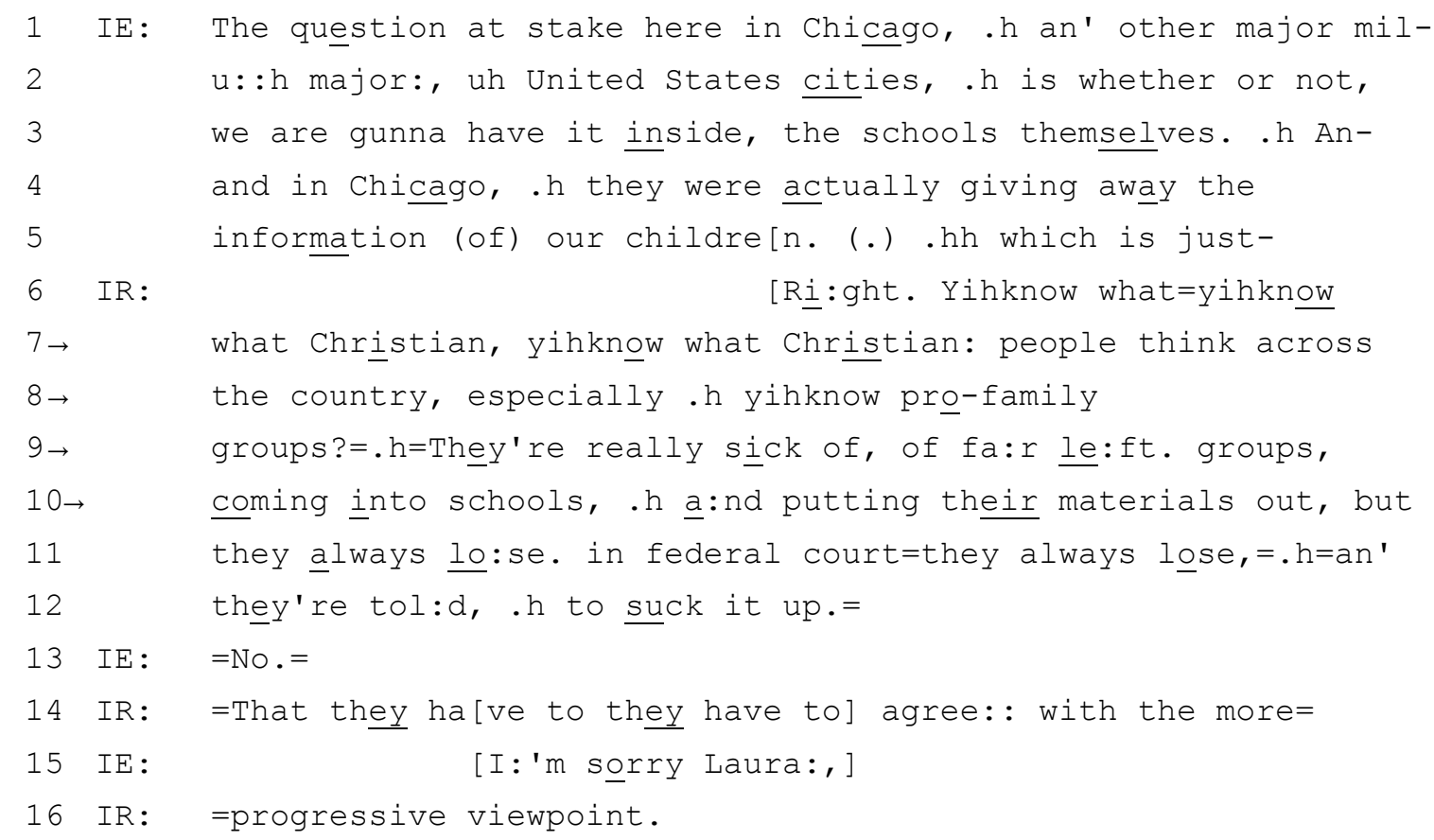

In this instance, tribuneship is indexed by means of a rhetorical question, 'yihknow 
what Chris:tian: people think...especially...pro-family groups?' The fact that this question is phrased declaratively, rather than in the interrogative form 'Do you know what Christian people think?', serves both to construct it as rhetorical, and to distribute alignments between the IE and IR. The phrasing suggests that the IR possesses her own knowledge of the answer; thus by knowing 'what Christian people think', the IR at least implicitly aligns herself with the category 'Christians' (and also 'pro-family groups'). Correspondingly, the wording of the question suggests that the IE does not know 'what Christian people think', and is therefore distanced from these groups. Moreover, the rest of IR's turn in which she produces the answer to this rhetorical question shows her casting Christian and pro-family groups in a sympathetic light: their complaints about 'fa:r le:ft. groups' are dismissed and they are told 'to suck it up'. The IR here speaks for a particular sectoral interest within the wider social structure; and by aligning herself with that sector, she attempts to position the IE negatively in alignment with 'non-Christian' and 'anti-family' groups.

In extract (8) we see another example of this kind of sectoral representation, this time in a more extreme form. The topic here is a recent spate of demonstrations and bomb attacks by pro-life activists at a Kansas abortion clinic, culminating in the shooting of its chief clinician, Dr Tiller. Previously the IR has pressed the IE ( a supporter of the clinic's activities) on whether she believes 'late term fetuses' should have human rights that protect them from abortion. The IE having evaded this question, the interview then turned to a critical report on the clinic's activities published following a formal investigation:

(8) TOF 12.6.09: Abortion clinic chief Tiller has been shot

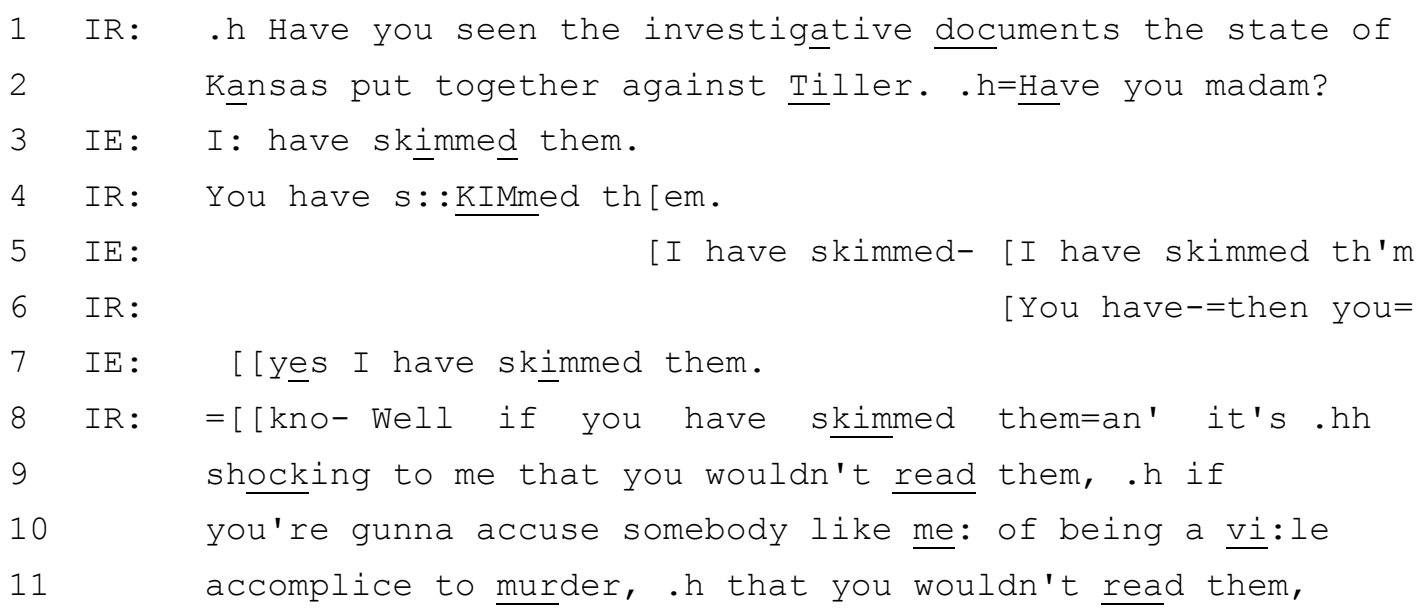




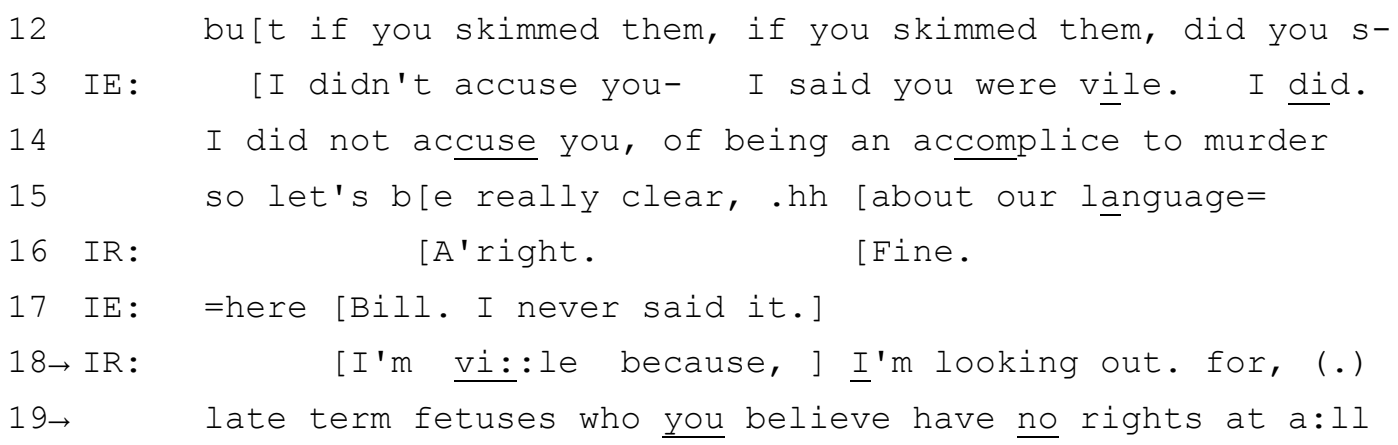

The IR refers to 'investigative documents...against Tiller' (line 1) and then takes issue with the IE's dismissive claim to have 'skimmed' them. In lines 10-11 he utilises this characterisation to challenge the IE's description of him, in a column published elsewhere, as a 'vi:le accomplice to murder'. This is in reference to his earlier reporting on the Kansas state investigation which had focused on the claim that, while not illegal, the clinic had been carrying out late term abortions for what the IR described as 'casual reasons' (indeed elsewhere in the interview, the IE quotes the IR referring to Tiller as 'a baby killer').

It is at this point that the IR does a form of tribuneship that, again, positions him as 'looking out for' a particular group in society and does corresponding alignment work for the IE. In lines 18-19, the IR acts as tribune not only for a sectoral interest, but for a sector who cannot, in fact, self-represent: 'late term fetuses'. In aligning himself with the interests of late term fetuses the IR also positions the IE in alignment with those responsible for the implied negative social standing of this group: 'who you believe have no rights at a:ll'.

In all of the above examples it is noticeable that the tribuneship move is made in the context of disagreement: not only disagreement of the IR with the IE's position, but expressions of disagreement and disavowal of attributed positions from the IE him or herself. Looking back at the API example presented in extract (4), it is the case there too that the IR's tribuneship move is done in the context of disagreeing with the IE's point about international law.

It therefore seems that tribuneship, in news interviews, may not simply be a means of adopting a populist stance or 'speaking for' the general public - or in the HPI, particular ideologically delineated sectors of the populace. It is a device whereby those extraneous 
interests are invoked in the construction of a dispute between IR and IE. In the CPI and API the device can enable a dispute still to be prosecuted neutralistically; while in the HPI, the IR's agency and alignment are foregrounded in disputes conducted non-neutralistically.

\section{Conclusion}

This article began from the standpoint that hybridity in news broadcasting needs to be understood in terms of the speech practices and speech exchange systems that shape what audiences encounter as 'the news'. In interviews in particular, it is possible to define a number of ways in which journalistic practices are hybridising as other forms and formats of talk-ininteraction come into play in addition to the normative question-answer-next question structure.

I identified four types of news interview interaction in the contemporary environment of political broadcasting: the conventional, adversarial, hybrid, and reflexive interviews. Focusing on the second and third of these, I showed how the hybrid political interview provides more extreme forms of talk than the adversarial (or accountability) interview on a number of dimensions including personal stance taking by IRs, attribution of responsibility and unhedged disagreement, use of personal insult, use of personal pro-terms, and emotionally heightened behaviour.

Finally, the differences between interviewer conduct in adversarial and hybrid interview types were further illustrated using the notion of tribuneship. What might be thought of as the classical sense of tribuneship - an appeal to the people or the people's interests - is often found in adversarial, accountability, and to a lesser extent conventional interview types. In the hybrid interview, in line with the more extreme forms of personalisation common to that type, there appears a different form of tribuneship in which the interviewer often takes up a stance on his or her own behalf as spokesperson for, or representative of, segments of a population which are brought into play rhetorically in order to pursue an argument with the interviewee. 


\section{References}

Atkinson, JM and Drew, P (1979) Order in Court. London: Macmillan.

Baym, G (2013) Transformations in hybrid TV talk: Extended interviews on The Daily Show(.com). In: Ekstrom, M and Tolson, A (eds) Media Talk and Political Elections in Europe and America. London: Palgrave Macmillan, pp.63-86.

Bull, P (2008) 'Slipperiness, evasion, and ambiguity': Equivocation and face-work in noncommittal political discourse. Journal of Language and Social Psychology, 27: 333-344. Clayman, S (1988) Displaying neutrality in television news interviews. Social Problems, 35(4): 474-492.

Clayman, S (1992) Footing in the achievement of neutrality: The case of news interview discourse. In: Drew, P and Heritage, J (eds) Talk At Work. Cambridge: Cambridge University Press, pp.163-198.

Clayman, S (2010) Address terms in the service of other actions. In: Thornborrow, J and Montgomery, M (eds) Special Issue on Personalisation in the Broadcast News Interview. Discourse and Communication, 4(2): 161-183.

Clayman, S and Heritage, J (2002) The News Interview. Cambridge: Cambridge University Press.

Clayman, S and Whalen, J (1988/9) When the medium becomes the message: The case of the Rather-Bush encounter. Research on Language and Social Interaction, 22: 241-272. Corner, J (1991) The interview as social encounter. In: Scannell, P (ed) Broadcast Talk. London: Sage, pp.31-47.

Coulter, J (1990) Elementary properties of argument sequences. In: Psathas, G (ed) Interaction Competence. Washington DC: University Press of America, pp.181-203. Ekstrom, M (2011) Hybridity as a resource and challenge in a talk show political interview. In: Ekstrom, M and Patrona, M (eds) Talking Politics in Broadcast News. Amsterdam: John Benjamins, pp.135-156.

Greatbatch, D (1986) Aspects of topical organisation in news interviews: The use of agenda- 
shifting procedures by interviewees. Media, Culture and Society, 8(4): 441-455.

Greatbatch, D (1988) A turn-taking system for British news interviews. Language in Society, 17(4): 401-430.

Harris, S (1991) Evasive action: How politicians respond to questions in political interviews. In: Scannell, P (ed) Broadcast Talk. London: Sage, pp.76-99.

Heritage, J (1985) Analysing news interviews: Aspects of the production of talk for an overhearing audience. In: van Dijk, T (ed) Handbook of Discourse Analysis, Volume 3: Discourse and Dialogue. London: Academic Press, pp.95-117.

Heritage, J, Clayman, S and Zimmerman, J (1988) Discourse and message analysis: The micro-structure of mass media messages. In: Hawkins, RP, Wiemann, JM and Pingree, S (eds) Advancing Communication Science: Merging Mass and Interpersonal Processes. London: Sage, pp.77-109.

Hutchby, I (1996) Confrontation Talk: Arguments, Asymmetries and Power on Talk Radio. Mahwah NJ: Lawrence Erlbaum Associates.

Hutchby, I (2011a) Non-neutrality and argument in the hybrid political interview. Discourse Studies, 13(3): 349-366.

Hutchby, I (2011b) Doing non-neutral: Belligerent interaction in the hybrid political interview. In: Ekstrom, M and Patrona, M (eds) Talking Politics in the Broadcast Media. Amsterdam: John Benjamins, pp.115-134.

Hutchby, I (2013) Obama in the no spin zone. In: Ekstrom, M and Tolson, A (eds) Media Talk and Political Elections in Europe and America. London: Palgrave Macmillan, pp.41-62. Hutchby, I and Wooffitt, R (2008) Conversation Analysis (2 ${ }^{\text {nd }}$ Edition). Cambridge: Polity Press.

Jefferson, G (1981) The abominable 'ne?': An exploration of the phenomenon of postresponse pursuit of response. Manchester Sociology Occasional Papers, 6: 1-82.

Lauerbach, G (2004) Political interviews as a hybrid genre. Text, 24(3): 353-397. Matheson, D (2005) Media Discourses: Analysing Media Texts. Maidenhead: Open University Press.

Meehan, E (2005) Why TV is Not our Fault: Television Programming, Viewers and Who's 
Really in Control. Lanham MD: Rowman and Littlefield.

Montgomery, M (2007) The Discourse of Broadcast News. London: Routledge.

Patrona, M (2011) Neutralism revisited: When journalists set new rules in political news discourse. In: Ekstrom, M and Patrona, M (eds) Talking Politics in Broadcast News.

Amsterdam: John Benjamins, pp.157-176.

Rendle-Short, J (2007) Neutralism and adversarial challenges in the political news interview. Discourse and Communication, 1(3): 387-406.

Sacks, H, Schegloff, EA and Jefferson, G (1974) A simplest systematics for the organisation of turn-taking for conversation. Language, 50(4): 696-735.

Schudson, M (1994) Question authority: A history of the news interview in American journalism, 1860s-1930s. Media, Culture and Society 16(4): 565-588.

Silvia, T (ed) (2001) Global News: Perspectives on the Information Age. Ames IA: Iowa State University Press.

Thornborrow, J and Montgomery, M (eds) (2010) Special Issue on Personalisation in the Broadcast News Interview. Discourse and Communication, 4(2): 99-219.

Thussu, DK (2007) News as Entertainment: The Rise of Global Infotainment. London: Sage. Tolson, A (ed) (2001) Television Talk Shows: Discourse, Performance, Spectacle. Mahwah NJ: Lawrence Erlbaum Associates. 